\title{
Current status of infarction in the basal ganglia-internal capsule due to mild head injury in children using PRISMA guidelines (Review)
}

\author{
GUANGMING WANG, YONGXIN LUAN, LU FENG and JINLU YU \\ Department of Neurosurgery, The First Hospital of Jilin University, Changchun, Jilin 130021, P.R. China
}

Received March 8 2019; Accepted November 8, 2019

DOI: $10.3892 /$ etm.2019.8320

\begin{abstract}
Post-traumatic basal ganglia-internal capsule (BGIC) infarction in pediatric patients is a relatively rare consequence of mild head injury (MHI). To the best of the authors' knowledge, at present, no comprehensive review has been published. To review research on BGIC infarction after MHI, a literature search was performed using the PubMed database and relevant search terms. According to recent data, MHI may cause BGIC infarction due to mechanical vasospasm of the perforating vessels in pediatric patients. The anatomical characteristics of the growing brain in infancy, mineralization of the lenticulostriate arteries and viral infection may all play a part in BGIC infarction after MHI, which often occurs within 24 months. Symptoms are not as severe and tend to disappear in the early period. Computed tomography or magnetic resonance imaging often shows BGIC infarction. There are also children with scattered calcification of the basal ganglia. Neural rehabilitation is a commonly accepted treatment. The prognosis of patients with BGIC infarction after MHI consistently improves.
\end{abstract}

\section{Contents}

1. Introduction

2. Illustrative case

3. Literature search and processing

4. Risk factors

5. Pathogenesis

6. Clinical features

7. Radiological features

8. Diagnosis

9. Treatment and prognosis

10. Conclusions

Correspondence to: Dr Jinlu Yu, Department of Neurosurgery, The First Hospital of Jilin University, 71 Xinmin Avenue, Changchun, Jilin 130021, P.R. China

E-mail: jlyu@jlu.edu.cn

Key words: infarction, basal ganglia-internal capsule, mild head injury, children

\section{Introduction}

Mild head injury (MHI), mostly presenting as brain concussion, is a common accident and usually does not result in severe complications (1). However, in some cases, MHI may lead to basal ganglia-internal capsule (BGIC) infarction and cause severe neurological deficits. BGIC infarction after MHI has rarely been described in children, and the morbidity of the disease is only $2-3 \%$ in all pediatric craniocerebral trauma $(2,3)$.

Despite a high incidence, reports of this entity are limited to case reports or small case series $(4,5)$. Currently, the frequency, cause, imaging changes and influence on mortality of BGIC infarction are not well defined (6). As such, limited information is available on BGIC. Hence, a literature search was conducted using the PubMed database and relevant search terms to review the research on BGIC infarction after MHI. The present review was organized following the Preferred Reporting Items for Systematic Reviews and Meta-Analyses (PRISMA) guidelines and was established as a systematic review (7). In this review, except for an illustrative case, the risk factors of infarction, pathophysiology, clinical and radiological features, diagnosis, treatment and prognosis were analyzed and delineated for BGIC infarction in children after MHI.

\section{Illustrative case}

A 1-year-old male boy was admitted in May 2018 to The First Hospital of Jilin University due to an inability to walk. He tripped over a baseball and lost his balance at kindergarten. The accident was a deceleration injury. Although he suffered an abrasion, he showed no signs of abnormal behavior. The child did not lose consciousness following the accident, but $5 \mathrm{~h}$ later developed left-sided weakness, involving the leg and arm. At admission, upon physical examination, the patient showed clear consciousness and could answer common questions. The pupils and relevant reflexes were normal. The power in the left lower limbs according to Medical Research Council grading was 3/5 (8). Head computed tomography (CT) scans at $6 \mathrm{~h}$ showed scattered calcification in the bilateral basal ganglia. Coronal and sagittal reconstruction showed linear calcification perpendicular to lateral fissure (Fig. 1). Magnetic resonance imaging (MRI) T2 showed bilateral basal ganglia infarction $7 \mathrm{~h}$ after trauma (Fig. 2A). No abnormalities were found in 
the internal carotid artery system by magnetic resonance angiogram (MRA; Fig. 2B). The male boy was diagnosed with post-traumatic BGIC. He was given rehabilitative treatment and a full recovery was made within 1 month. At the 6-month follow-up, his conditions had improved markedly and he had regained a power of $5 / 5$ in the affected limbs. Outcome assessed according to The Glasgow Outcome Scale was 5 (9).

\section{Literature search and processing}

The present systematic review was conducted in accordance with the PRISMA guidelines (7). Eligible English language articles (case reports, case series and studies considering BGIC infarction after MHI) were identified through searches of PubMed publications (the last search date was May 2019). The search algorithm used the terms 'basal ganglia-internal capsule,' 'mild head injury,' 'infarction' and 'children' as key words in relevant combinations. The reference lists of the identified articles were also manually searched for additional studies. The resulting flowchart is depicted in Fig. 3.

The inclusion criteria were as follows: i) Full text was available; ii) clinical data were complete; and iii) all of the cases in the articles were BGIC infarction after MHI. The studies without sufficient descriptions of BGIC infarction after MHI were excluded. After a review of the obtained literature, the current status of BGIC infarction after MHI was summarized in terms of risk factors, pathophysiology and pathology, clinical features, radiological features, treatment and prognosis.

\section{Risk factors}

The underlying mechanism leading to the increased incidence of BGIC infarction in pediatric patients has not been well described. The incidence of trauma in adults is higher than that in children, but the morbidity of BGIC is much lower in adults than in children (5). An increasing number of studies have focused on the peculiarity of the craniocerebral anatomy and the pathophysiology of the cerebral artery with traumatic basal ganglia region apoplexy in children $(1,4,5,10)$.

Course of the middle cerebral artery (MCA) and lenticulostriate arteries (LAs). An aged-related anatomical peculiarity of the cerebral artery may be a possible explanation for BGIC infarction in children, although the precise pathogenesis remains unclear (5). The BGIC is supplied by the LAs of the MCA; the LAs originating from the MCA can be divided into two segments: The subarachnoid space [extracerebral segments (ES)] and intracerebral segments (11). The mobile subarachnoid space segment, the ES, is between two fixed ends (proximal to the MCA and distal to the brain parenchyma) and is vulnerable to any sudden movement-induced stretching, inflicting trauma on the intima, resulting in vasospasm and/or thrombosis $(1,12)$. In normal conditions, the anatomical relationship between the LAs and the MCA trunk changes from fetal life through to childhood and adulthood $(13,14)$. In infancy, there is an acute angle between the MCA and the LAs. The lateral perforators are more acute than the medial ones, and this sharp angle becomes more obtuse during a person's lifetime (11). The length of these ES also tends to be shorter in younger individuals (15).
Based on the short ES and acute angle characteristics of the pediatric LA, the subarachnoid space segment of the LA in a child is more tensely stretched at an acute angle compared with that of an adult, and these arteries are functional end arteries; they are thus mechanically vulnerable to ischemia, even after MHI (16). The LA differences between children and adults are presented in Fig. 4.

Unmatured brain and skull. The development of brain tissue in children is not yet mature, and the subarachnoid space is relatively larger than adults', which allows relatively violent and rapid displacement between brain tissue and the skull base during traumatic impact, resulting in shearing injury of the LAs $(17,18)$. In addition, the young pediatric brain has greater mobility than the skull base because the sphenoid bone is underdeveloped and does not cover the temporal lobes completely, facilitating stretching of the LAs during MHI (19). Furthermore, due to the elasticity of the unmatured pediatric skull, the shearing forces are stronger (4).

Viral infection. The association between cytomegalovirus infection and stroke has been increasingly emphasized (20-22). For instance, varicella zoster infection causes vasculopathy and susceptibility to the development of thrombosis or vasospasm after MHI (14). It is possible that this viral infection leads to an increase in the brittleness of the LAs, which are most likely to cause BGIC infarction in the presence of external force (22). In addition, it is possible that viral infection, such as cytomegalovirus infection, could damage vascular endothelial cells and increase their susceptibility to developing arterial thrombosis or spasm following MHI (16).

Genetic factors. It was previously demonstrated that some children with BGIC have mutations in the calcium voltage-gated channel subunit $\alpha 1$ A gene, suggesting that vulnerability to adverse neurological sequelae following MHI may be genetically determined in some individuals (23). It is therefore possible that the children described in a previous study may have an underlying genetic susceptibility to vasospasm or intimal disruption following MHI (24).

Mineralization and vasculopathy of the LAs. Basal ganglia mineralization is also a major risk factor for cerebral infarction identified after MHI in children $(5,25,26)$. When mineralization exists, LAs are particularly vulnerable to transforming, stretching and distorting forces, which can be imposed even by MHI, making it easier to develop vasospasm and/or thrombosis $(4,27)$. Further research of the underlying cause of the mineralization of LAs is needed (28-31). The genetic factors or viral infection may be the cause, but further research is needed to explore the mechanisms underlying mineralizing angiopathy.

Previous studies have found idiopathic lesions in the arteria lenticularis, termed lenticulostriate vasculopathy (LSV), which could be detected by cranial ultrasound $(32,33)$. This is known to occur in $0.4 \%$ of all live-born neonates and in $1.9-5.8 \%$ of ill neonates (33). It has been reported to occur in association with a variety of congenital and acquired disorders and is known to regress over time (34). The pathology of LSV may involve mineralization of the hypercellular arterial wall; however, the 


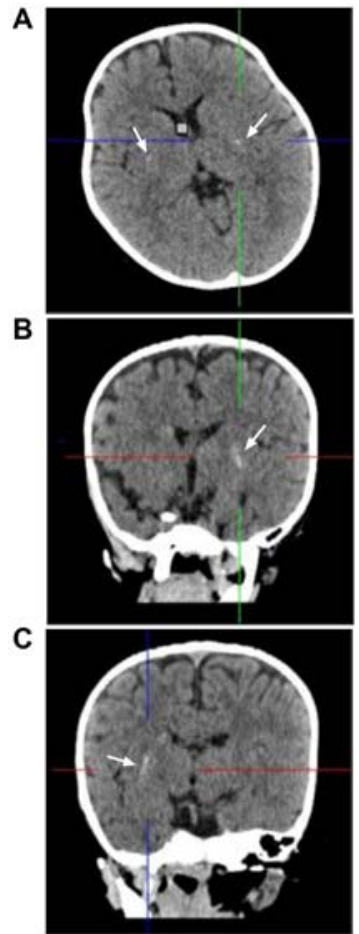

Figure 1. Computed tomography (CT) images of the illustrative case (A) Head CT in axial view shows bilateral symmetric scattered mineralization of the lenticulostriate arteries (arrows). (B) Coronal CT shows scattered mineralization of the left lenticulostriate artery (arrow). (C) Coronal CT shows scattered mineralization of the right lenticulostriate artery (arrow). The brain tissue of this children is not well-developed, and the subarachnoid space is relatively large (A-C).
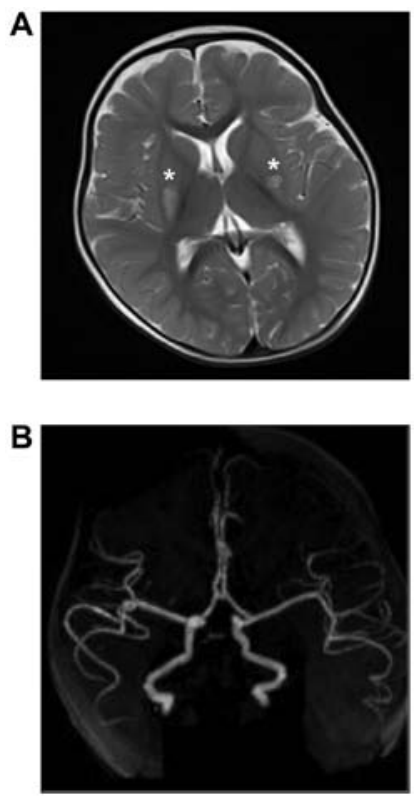

Figure 2. MRI of the illustrative case. (A) MRI T2 weighted image shows an infarct signal in the basal ganglia on either side (asterisks). (B) No abnormalities were found in the internal carotid artery system in the magnetic resonance angiogram. MRI, magnetic resonance imaging.

etiology is obscure (33). Cantey and Sisman (31) reported that, in infants initially identified with congenital infection, LSV was associated with a variety of infectious and noninfectious conditions. The congenital and acquired factors may lead to
Table I. Possible risk factors in the post-traumatic basal ganglia-internal capsule infarction.

\begin{tabular}{ll}
\hline Type of factor & \multicolumn{1}{c}{ Possible risk factors } \\
\hline Anatomic & $\begin{array}{l}\text { Course of lenticulostriate, unmatured brain } \\
\text { and skull, unmatured skull }\end{array}$ \\
Pathological & $\begin{array}{l}\text { Viral infection, genetic factors, mineralization } \\
\text { of lenticulostriate artery, idiopathic } \\
\text { lenticulostriate vasculopathy }\end{array}$ \\
\hline
\end{tabular}

endothelial dysfunction and vascular inflammation, as well as vascular smooth muscle cell proliferation (30). Therefore, it was hypothesized that congenital or acquired damage, for example viral infection, may cause LSV, and lenticulostriate calcification may be the end stage of LSV. The etiology needs to be further clarified. The risk factors are presented in Table I.

\section{Pathogenesis}

The occlusion of the perforating vessels of the MCA led to small infarctions in the BGIC $(26,27,35)$. The pathogenesis of post-traumatic occlusions of the MCA can be divided into four different types of lesions: Emboli from the cervical portion of the carotid artery, vasospasm, traumatic dissection and post-traumatic thrombosis (36). Some cases of BGIC infarction after MHI have a reversible nature, and it was hypothesized that mechanical spasm or thrombosis of the perforating vessels might play a role in the injury $(16,17,37-39)$.

The theory of vasoconstriction due to physical stimulation by direct stretching or mechanical irritation has been supported, and local inflammation inducing arterial narrowing has been demonstrated (40). Based on the aforementioned risk factors of BGIC, stretching or mechanically altering a vessel causes vasospasm and the thrombosis response, which may result in BGIC infarction (41).

\section{Clinical features}

History of trauma. In children with BGIC infarction, most suffer from minor injuries. The mechanism of trauma is different from that of high-speed injury, such as a motor vehicle crash, high-altitude crash injuries or abusive head trauma. It is noteworthy that most injuries are low-speed injuries. Most had a definite history of a fall from a low-altitude height, either from the lap of a mother, a chair, a bed, a table, fences, stairs or the child tripped while running $(17,33,35,42)$.

Age. Most children with BGIC infarction after MHI were $<2$ years of age (4). In a previous study by Yang et al (5), there was an association between BGIC infarction in children $<18$ months and recent MHI reported. However, BGIC infarction after MHI can occasionally occur in older children. For instance, in a previous study by Erbayraktar et al (43), the oldest child was a 12-year-old male.

Timing between onset and MHI. Most of the symptoms appeared between a few minutes and $6 \mathrm{~h}$, and there were 


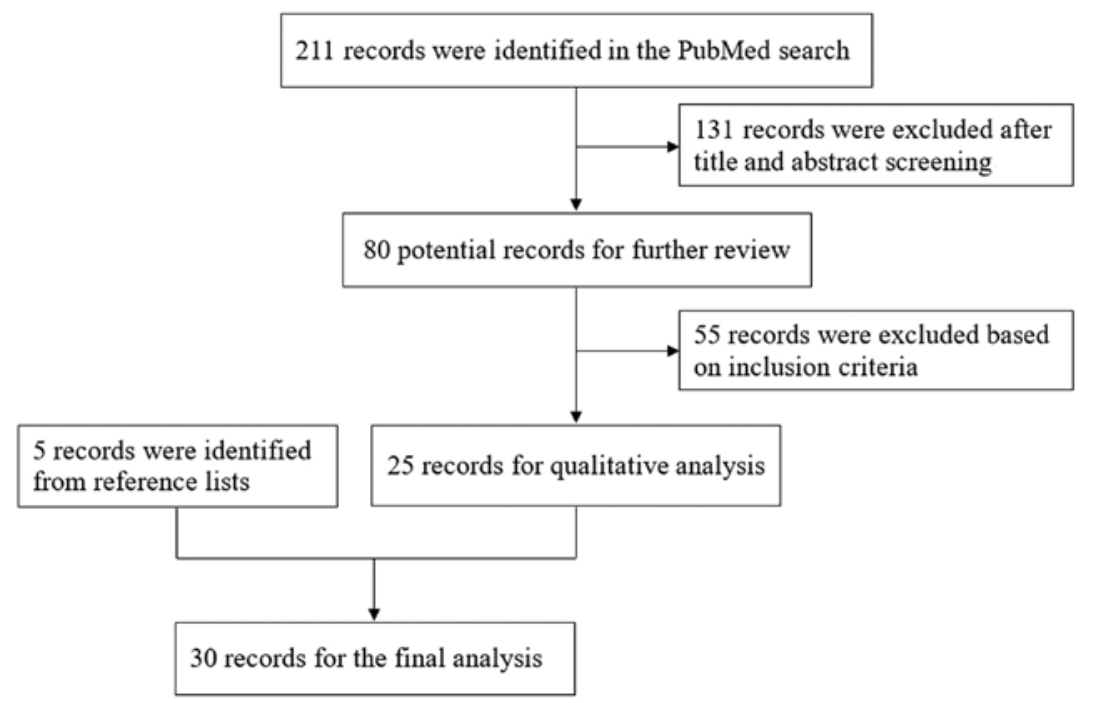

Figure 3. Flowchart showing how the present study was derived.

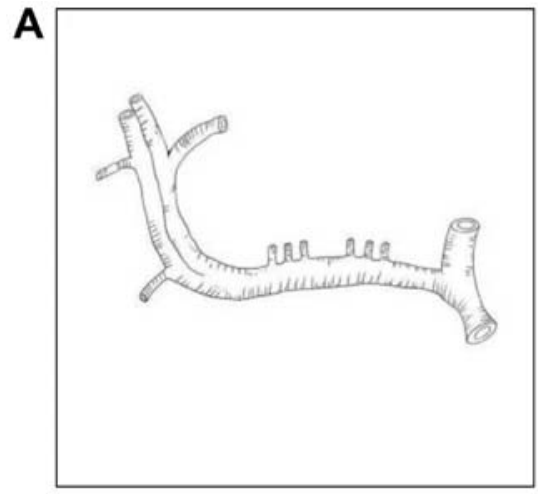

B

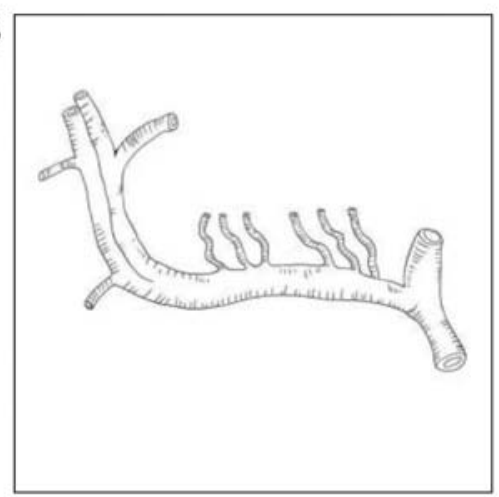

Figure 4. Mobile subarachnoid space segments of the lenticulostriate artery are more acute, shorter and more tensely stretched in (A) a child than in (B) an adult.

also reports of symptoms appearing 7 days after MHI $(2,26)$. For example, in a previous study by Jain et al (4) in 2015, the median time was $2 \mathrm{~h}$, with all children developing symptoms within $24 \mathrm{~h}$ after MHI.

Neurological defects. All children with BGIC had Glasgow Coma Scale scores (44) ranging from 13 to 15 . Most of the patients had MHI, often without loss of consciousness (17). After infarction occurred, contralateral hemiparesis presented with hemiplegic and facial paralysis, and some children appeared to have epileptic seizures (5). Otherwise, the associated findings of dysarthria, athetosis, and cognate and behavioral abnormalities are rarely reported (28). Occasionally, BGIC infarctions can occur on bilateral sides, and the weakness was only on one side (6). This observation is the same as that presented in the aforementioned illustrative case.

\section{Radiological features}

$C T$. Early CT scans showed no hypodense lesions, and late CT showed an infarct in the BGIC. In a CT scan, mineralization in a basal ganglion can be found; the calcification, remade by 3-D technology, shows linear pointing to the sylvian fissure (5).

Magnetic resonance (MR). MRI could find an infarction signal in a few hours after MHI (32); in some cases, bilateral infarcts were observed. In a MRA, the internal carotid artery and vertebral artery system are often normal. MR fiber tracking was helpful, which demonstrated that the severity of motor deficit depends on the extent of the infarct in the upper part of the internal capsule $(45,46)$.

Ultrasound. Children $<2$ years old with open fontanelle are scanned through the fontanel as a 'sound window'. Intracranial ultrasound often suggest hyperechogenicity that is consistent with the line of the LA (1). Ivanov et al (33) identified that coronal and parasagittal cerebral sonogram examinations demonstrated linear hyperechogenic LAs, which corresponded to the calcifications observed on CT. Lenticulostriate vasculopathy refers to increased echogenicity of the penetrating vessels that supply the basal ganglia and segments of the internal capsule seen on a cranial ultrasound $(1,33,35)$.

\section{Diagnosis}

In summary, the diagnostic criteria are as follows: (i) All children have a clear history of minor trauma; (ii) hemiplegia or 
facial paralysis often occurs within a few hours after trauma; and (iii) CT or MRI could show unilateral or bilateral infarction in some episodes. In children $<2$ years of age, ultrasound could sometimes detect strong echoes of the lenticular artery.

\section{Treatment and prognosis}

There is no consensus on the treatment of traumatic BGIC infarction in children. However, all the reported children were treated with conservative treatment, using aspirin at a dose of $3-5 \mathrm{mg} / \mathrm{kg}$ body once daily $(11,26,47)$. Ivanov et al $(33)$ used fresh frozen plasma infusion, dipiridamol, pyracetam and physiotherapy to treat the disease. In addition, post-traumatic rehabilitative physiotherapy is a safe and effective method $(5,26,48,49)$.

In previous studies, most children who experienced infarction after MHI recovered completely between 1 week and 3 months except for recurrence $(2,4)$. To the best of the authors' knowledge, there were no cases of death reported in the literature used in the present study. The median duration for complete recovery was 12 weeks for MHI. Neuronal plasticity during childhood, a theory describing the cellular potential for damaged neurons to recover and healthy neurons to reorganize, can account for marked recovery following BGIC infarction after MHI $(2,17)$.

\section{Conclusion}

MHI may cause BGIC infarction due to mechanical vasospasm of the perforating vessels in the pediatric age range. The anatomical characteristics of the growing brain in infancy, mineralization of the LAs and viral infection may all play a part in BGIC infarction after MHI, which often occurs within 24 months. Symptoms are not as severe and tend to disappear in the early period. CT or MRI often showed BGIC infarction. There are also children showing scattered calcification in the basal ganglia. In children $<2$ years of age, ultrasound could sometimes detect strong echoes of the lenticular artery. Neural rehabilitation is a commonly accepted treatment. The prognosis of patients with BGIC infarction after MHI consistently improves.

\section{Acknowledgements}

Not applicable.

\section{Funding}

No funding was received.

\section{Availability of data and materials}

The literature search was performed using the PubMed database and relevant search terms.

\section{Authors' contributions}

YL and LF searched the literature and analyzed the data. GW and JY designed the study and wrote the manuscript. All of the authors have read and approved the final manuscript.

\section{Ethics approval and consent to participate}

The case report received written consent.

\section{Patient consent for publication}

Not applicable.

\section{Competing interests}

The authors declare that they have no competing interests.

\section{References}

1. Nabika S, Kiya K, Satoh H, Mizoue T, Oshita J and Kondo H: Ischemia of the internal capsule due to mild head injury in a child. Pediatr Neurosurg 43: 312-315, 2007.

2. Kieslich M, Fiedler A, Heller C, Kreuz W and Jacobi G: Minor head injury as cause and co-factor in the aetiology of stroke in childhood: A report of eight cases. J Neurol Neurosurg Psychiatry 73: 13-16, 2002.

3. Provenzale JM and Sorensen AG: Diffusion-weighted MR imaging in acute stroke: Theoretic considerations and clinical applications. AJR Am J Roentgenol 173: 1459-1467, 1999.

4. Jain P, Kishore P, Bhasin JS and Arya SC: Mineralizing angiopathy with basal ganglia stroke in an infant. Ann Indian Acad Neurol 18: 233-234, 2015

5. Yang FH, Wang H, Zhang JM and Liang HY: Clinical features and risk factors of cerebral infarction after mild head trauma under 18 months of age. Pediatr Neurol 48: 220-226, 2013.

6. Mirvis SE, Wolf AL, Numaguchi Y, Corradino G and Joslyn JN: Posttraumatic cerebral infarction diagnosed by CT: Prevalence, origin, and outcome. AJR Am J Roentgenol 154: 1293-1298, 1990.

7. Hutton B, Salanti G, Caldwell DM, Chaimani A, Schmid CH, Cameron C, Ioannidis JP, Straus S, Thorlund K, Jansen JP, et al: The PRISMA extension statement for reporting of systematic reviews incorporating network meta-analyses of health care interventions: Checklist and explanations. Ann Intern Med 162: 777-784, 2015.

8. James MA: Use of the medical research council muscle strength grading system in the upper extremity. J Hand Surg 32: 154-156, 2007.

9. McMillan T, Wilson L, Ponsford J, Levin H, Teasdale G and Bond M: The glasgow outcome scale - 40 years of application and refinement. Nat Rev Neurol 12: 477-485, 2016.

10. Seals DR, Johnson DG and Fregosi RF: Hypoxia potentiates exercise-induced sympathetic neural activation in humans. J Appl Physiol (1985) 71: 1032-1040, 1991.

11. Marinkovic SV, Milisavljevic MM, Kovacevic MS and Stevic ZD: Perforating branches of the middle cerebral artery. Microanatomy and clinical significance of their intracerebral segments. Stroke 16: 1022-1029, 1985.

12. Rana KS, Behera MK and Adhikari KM: Ischemic stroke following mild head injury is it the cause. Indian Pediatr 43: 994-997, 2006.

13. Kodama N and Suzuki J: Cerebrovascular moyamoya disease. IIIrd report-the study on the aging of the perforating branches and the possibility of collateral pathway. Neurol Med Chir (Tokyo) 14: 55-67, 1974.

14. Buompadre MC, Arroyo HA and Stroke G: Basal ganglia and internal capsule stroke in childhood-risk factors, neuroimaging, and outcome in a series of 28 patients: A tertiary hospital experience. J Child Neurol 24: 685-691, 2009.

15. Donzelli R, Marinkovic S, Brigante L, de Divitiis O, Nikodijevic I, Schonauer C and Maiuri F: Territories of the perforating (lenticulostriate) branches of the middle cerebral artery. Surg Radiol Anat 20: 393-398, 1998.

16. Shaffer L, Rich PM, Pohl KR and Ganesan V: Can mild head injury cause ischaemic stroke? Arch Dis Child 88: 267-269, 2003.

17. Dharker SR, Mittal RS and Bhargava N: Ischemic lesions in basal ganglia in children after minor head injury. Neurosurgery 33: 863-865, 1993.

18. Mosberg WH and Lindenberg R: Traumatic hemorrhage from the anterior choroidal artery. J Neurosurg 16: 209-221, 1959. 
19. Landi A, Marotta N, Mancarella C, Marruzzo D, Salvati M and Delfini R: Basal ganglia stroke due to mild head trauma in pediatric age - clinical and therapeutic management: A case report and 10 year literature review. Ital J Pediatr 37: 2, 2011.

20. Huang ZR, Yu LP, Yang XC, Zhang F, Chen YR, Feng F, Qian XS and Cai J: Human cytomegalovirus linked to stroke in a chinese population. CNS Neurosci Ther 18: 457-460, 2012.

21. Grau AJ, Urbanek C and Palm F: Common infections and the risk of stroke. Nat Rev Neurol 6: 681-694, 2010.

22. Bodensteiner JB, Hille MR and Riggs JE: Clinical features of vascular thrombosis following varicella. Am J Dis Child 146: 100-102, 1992.

23. Kors EE, Terwindt GM, Vermeulen FL, Fitzsimons RB, Jardine PE, Heywood P, Love S, van den Maagdenberg AM, Haan J, Frants RR and Ferrari MD: Delayed cerebral edema and fatal coma after minor head trauma: Role of the CACNA1A calcium channel subunit gene and relationship with familial hemiplegic migraine. Ann Neurol 49: 753-760, 2001.

24. Jauhari P, Sankhyan N, Khandelwal N and Singhi P: Childhood basal ganglia stroke and its association with trivial head trauma. J Child Neurol 31: 738-742, 2016.

25. Fidan E, Cummings DD and Manole MD: A case of lenticulostriate stroke due to minor closed head injury in a 2-year-old child: Role of mineralizing angiopathy. Pediatr Emerg Care 34: e233-e235, 2017

26. Lingappa L, Varma RD, Siddaiahgari S and Konanki R: Mineralizing angiopathy with infantile basal ganglia stroke after minor trauma. Dev Med Child Neurol 56: 78-84, 2014.

27. Yang FH, Wang H, Zhang JM and Liang HY: Cerebral infarction after mild head trauma in children. Indian Pediatr 50: 875-878, 2013.

28. Caplan LR, Schmahmann JD, Kase CS, Feldmann E, Baquis G, Greenberg JP, Gorelick PB, Helgason C and Hier DB: Caudate infarcts. Arch Neurol 47: 133-143, 1990.

29. Deveber G: Stroke in infancy: A convergence of causes. Dev Med Child Neurol 56: 9-10, 2014

30. Kowalik TF, Wing B, Haskill JS, Azizkhan JC, Baldwin AS Jr and Huang ES: Multiple mechanisms are implicated in the regulation of NF-kappa B activity during human cytomegalovirus infection. Proc Natl Acad Sci USA 90: 1107-1111, 1993.

31. Cantey JB and Sisman J: The etiology of lenticulostriate vasculopathy and the role of congenital infections. Early Hum Dev 91: 427-430, 2015

32. Ishihara $\mathrm{C}$, Sawada $\mathrm{K}$ and Tateno A: Bilateral basal ganglia infarction after mild head trauma. Pediatr Int 51: 829-831, 2009.

33. Ivanov I, Zlatareva D, Pacheva I and Panova M: Does lenticulostriate vasculopathy predipose to ischemic brain infarct? A case report. J Clin Ultrasound 40: 607-610, 2012.

34. Coley BD, Rusin JA and Boue DR: Importance of hypoxic/ischemic conditions in the development of cerebral lenticulostriate vasculopathy. Pediatr Radiol 30: 846-855, 2000.
35. Masuzawa H, Kubo T, Kanazawa I, Kamitani H and Nakamura N: Shearing injuries of parasagittal white matter, corpus callosum and basal ganglia: Possible radiological evidences of hemiplegia in diffuse axonal injury. No Shinkei Geka 25: 689-694, 1997 (In Japanese).

36. Hollin SA, Sukoff MH, Silverstein A and Gross SW: Post-traumatic middle cerebral artery occlusion. J Neurosurg 25: 526-535, 1966.

37. Seckin H, Demirci AY, Degerliyurt A, Dagli M and Bavbek M: Posttraumatic infarction in the basal ganglia after a minor head injury in a child: Case report. Turk Neurosurg 18: 415-419, 2008.

38. Symon L: An experimental study of traumatic cerebral vascular spasm. J Neurol Neurosurg Psychiatry 30: 497-505, 1967.

39. Boto GR, Lobato RD, Rivas JJ, Gomez PA, de la Lama A and Lagares A: Basal ganglia hematomas in severely head injured patients: Clinicoradiological analysis of 37 cases. J Neurosurg 94: 224-232, 2001.

40. Zurynski YA and Dorsch NW: A review of cerebral vasospasm. Part IV. Post-Traumatic vasospasm. J Clin Neurosci 5: 146-154, 1998.

41. Kramer DR, Winer JL, Pease BA, Amar AP and Mack WJ Cerebral vasospasm in traumatic brain injury. Neurol Res Int 2013: 415813, 2013.

42. Ahn JY, Han IB, Chung YS, Yoon PH and Kim SH: Posttraumatic infarction in the territory supplied by the lateral lenticulostriate artery after minor head injury. Childs Nerv Syst 22: 1493-1496, 2006.

43. Erbayraktar S, Tekinsoy B, Acar F and Acar U: Posttraumatic isolated infarction in the territory of heubner's and lenticulostriate arteries: Case report. Kobe J Med Sci 47: 113-121, 2001.

44. Teasdale G, Maas A, Lecky F, Manley G, Stocchetti N and Murray G: The glasgow coma scale at 40 years: Standing the test of time. Lancet Neurol 13: 844-854, 2014.

45. Kim HC, Choi DP, Ahn SV, Nam CM and Suh I: Six-year survival and causes of death among stroke patients in Korea. Neuroepidemiology 32: 94-100, 2009.

46. Lee K, Kim EH, Song D, Kim YD, Nam HS, Lee HS and Heo JH: Lenticulostriate artery involvement is predictive of poor outcomes in superficial middle cerebral artery territory infarction. Yonsei Med J 58: 123-130, 2017.

47. Anderson V, Catroppa C, Morse S, Haritou F and Rosenfeld J: Functional plasticity or vulnerability after early brain injury? Pediatrics 116: 1374-1382, 2005.

48. Ogrenci A, Eksi MS, Gun B and Koban O: Traumatic basal ganglia hematoma following closed head injuries in children. Childs Nerv Syst 32: 1237-1243, 2016.

49. Kurwale NS, Gupta DK and Mahapatra AK: Outcome of pediatric patients with traumatic basal ganglia hematoma: Analysis of 21 cases. Pediatr Neurosurg 46: 267-271, 2010.

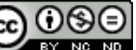

This work is licensed under a Creative Commons Attribution-NonCommercial-NoDerivatives 4.0 International (CC BY-NC-ND 4.0) License. 